\title{
ROTORCRAFT IN THE PERFORMANCE BASED NAVIGATION INTERNATIONAL CIVIL AVIATION ORGANIZATION IMPLEMENTATION
}

\author{
Andrzej Fellner, Robert Konieczka \\ The Silesian University of Technology \\ afellner@o2.pl,robert.konieczka@polsl.pl
}

\begin{abstract}
European Commision adopted in July new regulations about laying down airspace usage requirements and operating procedures concerning performance based navigation. It is next step in realization of the the global program PBN ICAO. At the 36th General Assembly of ICAO held in 2007, the Republic of Poland agreed to ICAO resolution A36-23 which urges all States to implement $\mathrm{PBN}$. In future aviation concepts the use of Performance Based Navigation (PBN) is considered to be a major Air Traffic Management (ATM) concept element. ICAO has drafted standards and implementation guidance for PBN in the ICAO Doc 9613 "PBN Manual". The Based Performance Navigation Concept represents and shift from sensor-based to performance based navigation connected with criteria for navigation: accuracy, integrity, availability, continuity and functionality depending on the phase of the flight. Through PBN and changes in the communication, surveillance and ATM domain, many advanced navigation applications are possible to improve airspace efficiency, improve airport sustainability, reduce the environmental impact of air transport in terms of noise and emission, increase safety and improve flight efficiency.
\end{abstract}

Keywords: PBN, ATM, integrity, accuracy, continuity, availability.

\section{INTRODUCTION - FACTORS DETERMINING AVIATION ACTION}

Dynamic development of science and technology is a cause of the universal implementation of techniques and satellite technologies and the appearance of the new specialization satellite navigation. It is specialization of the radio navigation, theory about leading objects in the ecosphere of the infrastructure landed and essential for planning and applying, based on radio signals assurances transmitted through satellite systems, to the purpose of accurate, reliable and safe achieving the function of the aim of this transferring. At present techniques and satellite technologies are universally used in different sphere of activities (Fig. 1). 
Fundamentally it is possible to divide factors determining air activity in three fundamental groups: $\Rightarrow$ Legislative:

- regulations of the European Parliament and the European Council,

- international agreements,

- international programs (Galileo, Singles European Sky, SESAR, Global Air Navigation Plan 2016-2030),

- domestic standard acts,

- national strategies (Strategy of the Development of Country 2020, Strategy of the Development of the Transport to 2020 with the perspective to 2030, Transport Politics of you for years 2006-2025, Program of the development of the chain of airports and air ground devices),

$\Rightarrow$ Functional:

- thickening communications trails and the need of ensuring security,

- demand for accurate data,

- fight against natural disasters, environmental protection,

- change of the preference of passengers concerning prices and choice of the type of means of transport,

- tourism and recreation,

$\Rightarrow$ Technical:

- general availability of techniques and satellite technologies,

- computerization of every sphere of activity of the man,

- implementation of advanced software, artificial intelligence,

- using the innovation of aviation companies.

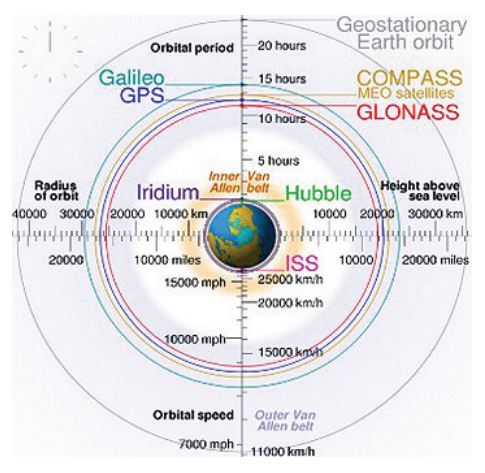

Fig. 1. Comparing orbits of satellites GPS, GLONASS, Compass and Galileo with orbits of Iridium satellites, Telescope Hubble'a, International Station Cosmic (source: Geo Swan, Commons repository free of charge).

universal access, the smaller minimal operating requirements for airports, greater elasticity of selection of the route, an additional source of information navigational, possibility of applying where he isn't able to provide the classical navigational assistance, cheap because not requiring the extra ground infrastructure, environmentally friendly (fuel, time of the flight, noise), for applying the flight in all phases. However he/she requires the right infrastructure and legal regulations. Poland

To mark belongs, that PBN for the third estate level in the development of the navigation, i.e. the passage from sensor data for holding defined for aircraft values of parameters (accuracy, credibility, availability, continuity) depending on the stage carried out of the flight (Fig. 2). PBN requires the appropriate deck equipment (Fig. 3), because constitutes the RNP expansion at simultaneous global RNAV [1] assuring and determining applied specifications and navigational applications is widening the scope of requirements considerably embracing with them:

- radio navigation system (accuracy, credibility, continuity, availability),

- equipment and the NAV functionality of the aircraft,

- certification criteria concerning the groundstaff and deck,

- III category within the scope of precise final approaches.

The party in the global air transport of the PBN program causes the number of the benefit in different sphere of activities of the man. Undoubtedly they belong to them: the global reach and the

(n)


accepting the resolution A37-11 ICAO was obligated to the PBN implementation and procedures of the RNAV GNSS final approach [2]. The Implementation of techniques and satellite technologies as part of obligations assumed by our country required raising competent funds and conducting appropriate examinations and the validation of achieved results at the air operating work. Therefore Poland Agency of the Air Navigation cooperating with the author she got appropriate centres as well as conducted the research in 2009-2014 years as part of three international projects carried out: HEDGE (Helicopter Deploy GNSS in Europe) [3], EGNOS APV Mielec (EGNOS Introduction in the European Eastern Region) [4], SHERPA (ad-Hoc support act it Eastern Region Preoperational Actions in GNSS). Achieved results and their operating validation in the Polish airspace enabled to validate the assumptions associated with the PBN implementation and to place in AIP POLAND twenty one of NPA RNAV GNSS [5] procedures for Polish airports controlled. Next acting according to ICAO Assoc. Prof. 9613 „PBN Manual” [6] was drawn up Polish version of implementing the navigation dokładnościowej „PBN Implementation POLAND” Plan, adopting new navigational criteria while investigation acting: the accuracy, the credibility, the availability, the continuity and the functionality. As part of projects they drew up and on the European forum documents constituting the base to the perspective PBN implementation were approved:

- SHERPA-PANSA-NMA-D 11 EP EGNOS POLAND MAKET ANALYSIS;

- SHERPA-PANSA-NSR-D 21 EP Polish National Scenario Contango;

- SHERPA-PANSA-ENIP-D 22 EP EGNOS National Implementation Plan.

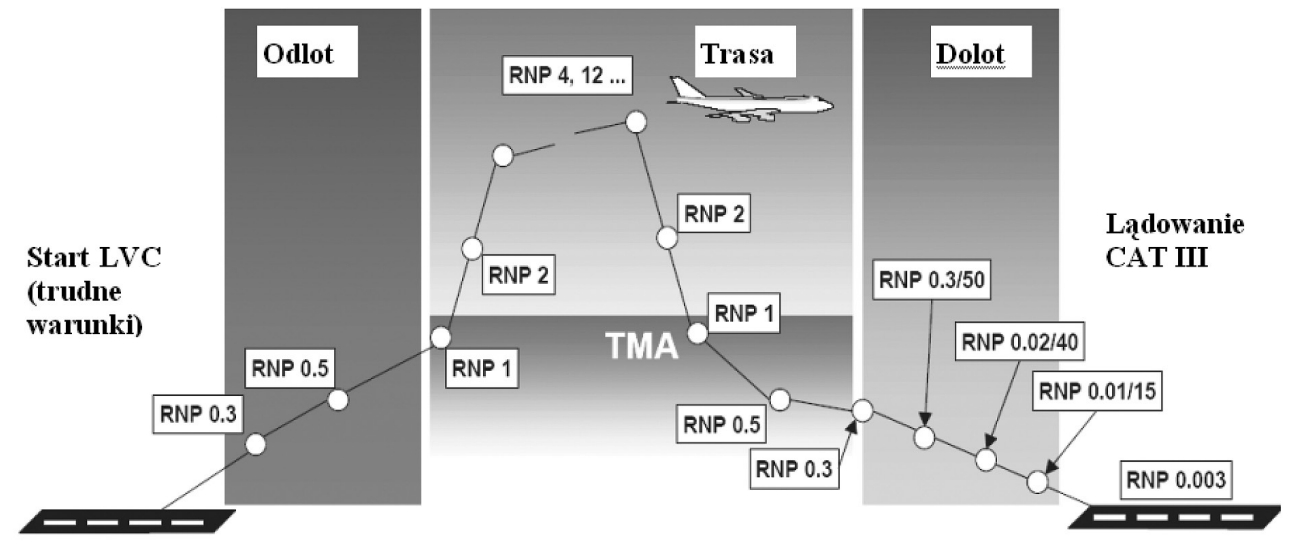

Fig. 2. The scheme of stages of the flight and the required parameter of the RNP accuracy.

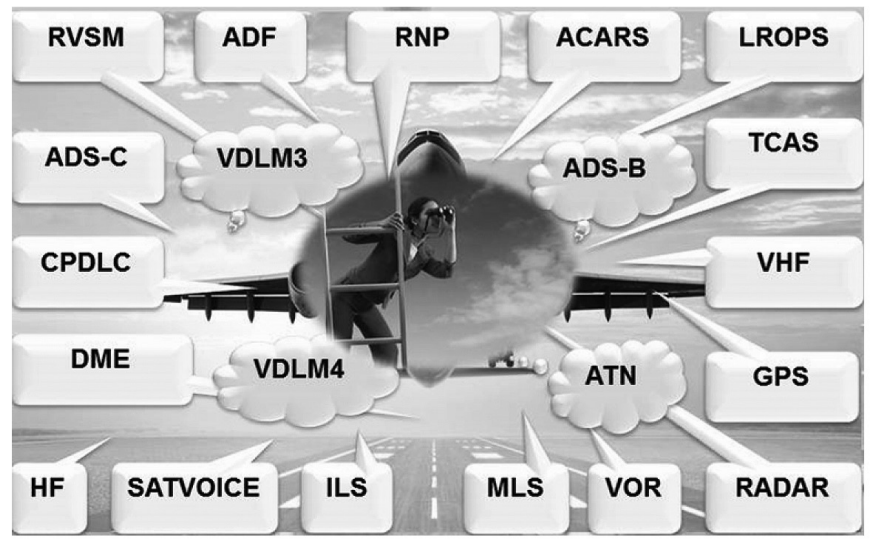

Fig. 3. Pilotage and navigational equipping with deck systems. 
PBN is closely associated with the following techniques and technologies: with satellite navigation (GNSS - Globar Navigation Satellite System)), with geographical information about the area (G sharp), with international system of the geographical information (IGS). It results from the European policy of the modality of the transport, of effective applying different means of transport in the destination of leading to optimum (economically, financially, level of provided services, environmental protection) and of balanced using resources. Essential GNSS isn't a homogeneous system, they also assumed that according to ICAO the GNSS system consist of the following elements (Fig. 4):

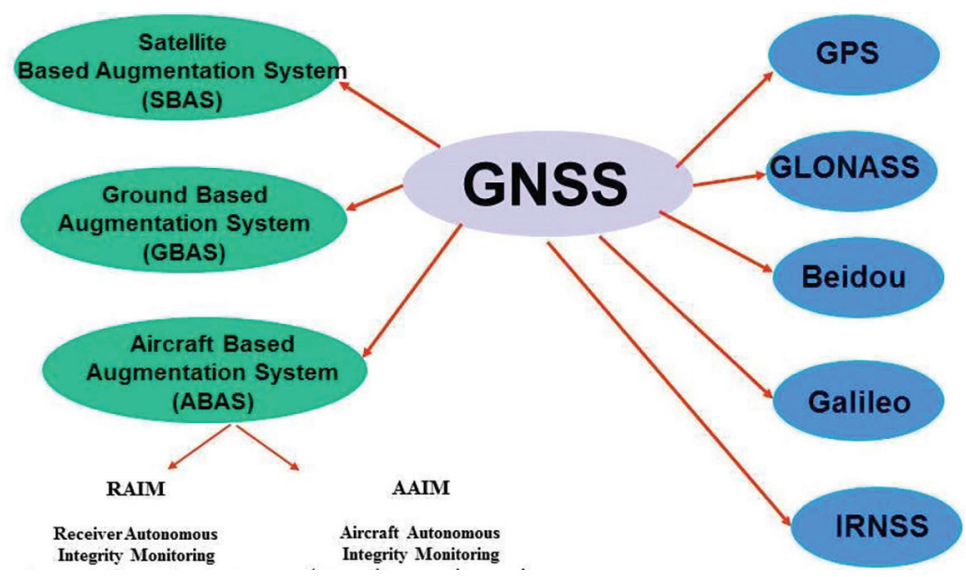

Fig. 4. Component elements of the GNSS system

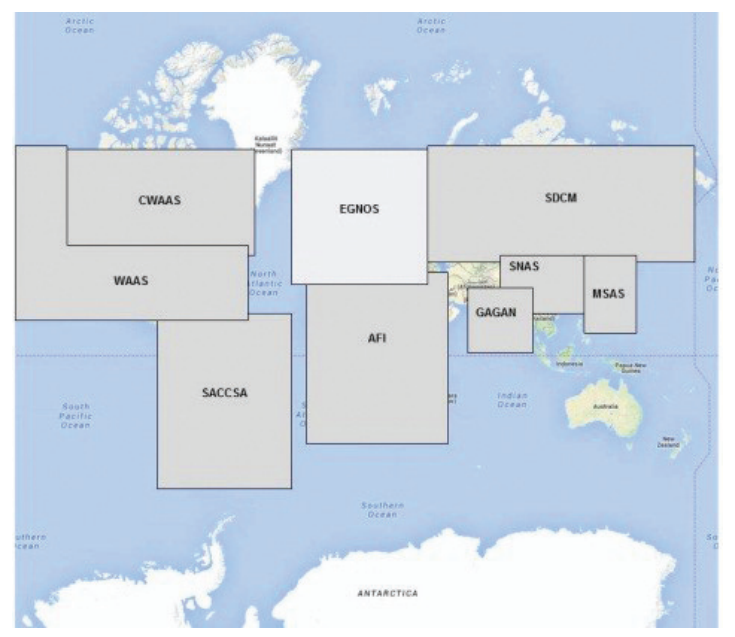

Fig. 5. Functioning and developed systems of Satellite Based Augmentation System a. satellite systems: GPS NAVSTAR (ang. Global Positioning System NAVigation Signal Timing and Ranging), GLONASS (ros. RГЛОНАСС - Глобальная навигационная спутниковая система), BeiDou/Compass, IRNSS (Indian Regional Navigational Satellite System), Galileo;

b. three support systems: SBAS (Satellite Based Augmentation System) Fig. 5, GBAS (Ground Based Augmentation System), ABAS (Airborne Based Augmentation System) being characterized: AAIM (Aircraft Autonomous Integrity Monitoring) and RAIM (Receiver Autonomous Integrity Monitoring).

\section{OUTLINE PERFORMANCE BASED NAVIGATION CONCEPT}

In future aviation concepts the use of Performance Based Navigation (PBN) is considered to be a major Air Traffic Management (ATM) concept element. ICAO has drafted standards and implementation guidance for PBN in the ICAO Doc 9613 "PBN Manual". The Based Performance Navigation Concept represents and shift from sensor-based to performance based navigation connected with criteria for navigation (Fig. 6) accuracy, integrity, availability, continuity and functionality 
(tab. 1) depending on the phase of the flight. Through PBN and changes in the communication, surveillance and ATM domain, many advanced navigation applications are possible to improve airspace efficiency, improve airport sustainability, reduce the environmental impact of air transport in terms of noise and emission, increase safety and improve flight efficiency.

It is evident that the application of GNSS will become even more common within the next decade. This calls for a preparation of the corresponding navigation infrastructure as well as (inter) national regulations and policy to facilitate the use of (augmented) GNSS during all phases

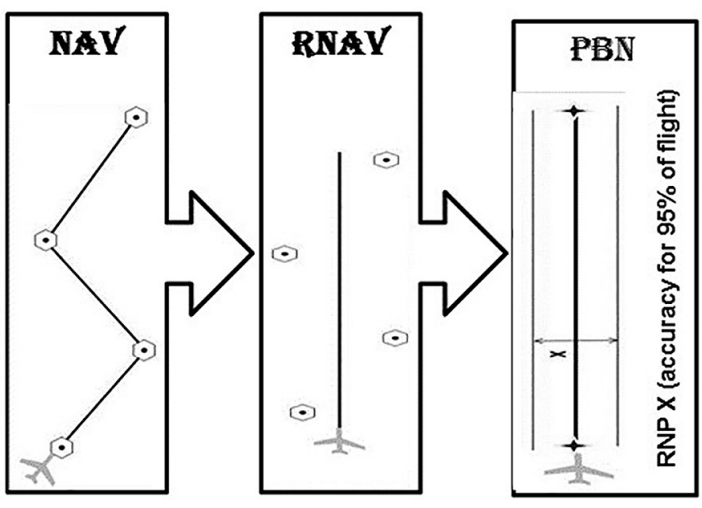

Fig. 6. Steps of the navigation: NAV - STANDARD (SENSOR), RNAV - AREA (RANDOM), PBN EXACTITUDE. of flight.

Tab. 1. Criteria for navigation.

\begin{tabular}{|c|c|c|c|c|c|c|}
\cline { 2 - 7 } \multicolumn{1}{c|}{} & $\begin{array}{c}\text { Lateral } \\
\text { Accuracy } \\
95 \%\end{array}$ & $\begin{array}{c}\text { Vertical } \\
\text { Accuracy } \\
95 \% \\
(1)(3)\end{array}$ & $\begin{array}{c}\text { Integrity } \\
(2)\end{array}$ & $\begin{array}{c}\text { Time to } \\
\text { Alert (3) }\end{array}$ & $\begin{array}{c}\text { Continuity } \\
(4)\end{array}$ & $\begin{array}{c}\text { Availability } \\
(5)\end{array}$ \\
\hline En-Route & $2 \mathrm{NM}(6)$ & $\mathrm{N} / \mathrm{A}$ & $1-10^{-7} / \mathrm{h}$ & $5 \mathrm{~min}$ & $\begin{array}{c}1-10^{-4} / \mathrm{h} \text { to } \\
1-10^{-8} / \mathrm{h}\end{array}$ & $\begin{array}{c}0.99 \text { to } \\
0.99999\end{array}$ \\
\hline ER, Terminal & $0.4 \mathrm{NM}$ & $\mathrm{N} / \mathrm{A}$ & $1-10^{-7} / \mathrm{h}$ & $15 \mathrm{~s}$ & $\begin{array}{c}1-10^{-4} / \mathrm{h} \text { to } \\
1-10^{-8} / \mathrm{h}\end{array}$ & $\begin{array}{c}0.99 \text { to } \\
0.99999\end{array}$ \\
\hline $\begin{array}{c}\text { Initial and } \\
\text { Intermediate } \\
\text { Approach, } \\
\text { NPA, SID }\end{array}$ & $220 \mathrm{~m}$ & $\mathrm{~N} / \mathrm{A}$ & $1-10^{-7} / \mathrm{h}$ & $10 \mathrm{~s}$ & $\begin{array}{c}1-10^{-4} / \mathrm{h} \text { to } \\
1-10^{-8} / \mathrm{h}\end{array}$ & $\begin{array}{c}0.99 \text { to } \\
0.99999\end{array}$ \\
\hline APV-I & $16.0 \mathrm{~m}$ & $20 \mathrm{~m}$ & $\begin{array}{c}1-2 \times 10^{-7} / \mathrm{h} \\
\text { per } \\
\text { approach }\end{array}$ & $10 \mathrm{~s}$ & $\begin{array}{c}1-8 \times 10^{-6} \text { in } \\
\text { any } 15 \mathrm{~s}\end{array}$ & $\begin{array}{c}0.99 \text { to } \\
0.99999\end{array}$ \\
\hline APV-II & $16.0 \mathrm{~m}$ & $8.0 \mathrm{~m}$ & $\begin{array}{c}1-2 \times 10^{-7} / \mathrm{h} \\
\text { per } \\
\text { approach }\end{array}$ & $6 \mathrm{~s}$ & $\begin{array}{c}1-8 \times 10^{-6} \text { in } \\
\text { any } 15 \mathrm{~s}\end{array}$ & $\begin{array}{c}0.99 \text { to } \\
0.99999\end{array}$ \\
\hline PA- CATI (8) & $16.0 \mathrm{~m}$ & $\begin{array}{c}6.0 \mathrm{~m} \text { to } \\
4.0 \mathrm{~m}(7)\end{array}$ & $\begin{array}{c}1-2 \times 10^{-7} / \mathrm{h} \\
\text { per } \\
\text { approach }\end{array}$ & $6 \mathrm{~s}$ & $\begin{array}{c}1-8 \times 10^{-6} \text { in } \\
\text { any } 15 \mathrm{~s}\end{array}$ & $\begin{array}{c}0.99 \text { to } \\
0.99999\end{array}$ \\
\hline
\end{tabular}

The concept of PBN relies on the use of an area navigation (RNAV) system. PBN relies on the use of area navigation and comprises of three components:

- the navigation application which identifies the navigation requirements resulting from the Airspace Concept such as ATS routes and Instrument Flight Procedures;

- the NAVAID Infrastructure which refers to ground and space-based navigation aids;

- the navigation specification which is a technical and operational specification that identifies the required functionality of the area navigation equipment. It also identifies how the navigation equipment is expected to operate in the NAVAID Infrastructure to meet the operational needs identified in the Airspace Concept. The navigation specification - is either an RNP specification or an RNAV specification. An RNP specification includes a requirement for on-board self-contained performance monitoring and alerting, while an RNAV specification does not. Designation of RNP and RNAV 
specifications for oceanic, remote, en-route and terminal operations (tab. 2):

RNP - specification is designated as RNP X, means the aircraft can follow a pre-defined track with $\mathrm{X}$ nautical miles accuracy $95 \%$ of the time and there is on-board monitoring and alerting that warns the pilot if accuracy is insufficient

RNAV - specification is designated as RNAV X, means the aircraft can follow a pre-defined track with $\mathrm{X}$ nautical miles accuracy $95 \%$ of the time.

If two navigation specifications share the same value for $\mathrm{X}$, they may be distinguished by use of a prefix, e.g. Advanced-RNP 1 and Basic-RNP 1. For both RNP and RNAV designations, the expression "X" (where stated) refers to the lateral navigation accuracy in nautical miles, which is expected to be achieved at least 95 per cent of the flight time by the population of aircraft operating within the airspace, route or procedure (Fig. 7). One should remember, that lateral navigation errors (Fig. 8), ( $95 \%$ of flight time) is characterized by the Total System Error (TSE), which is determine the Root Sum Square (RSS) of 3 errors: Path Definition Error (PDE), Navigation Sensor Error (NSE) and Path Definition Error (FTE). The navigation accuracy the aircraft achieves in practice is known as the Achieved Navigational Performance (ANP). Replies to the question: why system the GPS needs based augmentation system present Fig. 9.

Tab. 2. Navigation specifications by flight phase and associated EASA material.

\begin{tabular}{|c|c|c|c|c|c|c|c|c|c|}
\hline \multirow{3}{*}{$\begin{array}{l}\text { Navigation } \\
\text { Specifica- } \\
\text { tion }\end{array}$} & \multicolumn{8}{|c|}{ Flight Phase } & \multirow{3}{*}{$\begin{array}{c}\text { EASA } \\
\text { Material }\end{array}$} \\
\hline & \multicolumn{2}{|c|}{ En route } & \multirow[b]{2}{*}{ Arrival } & \multicolumn{4}{|c|}{ Approach } & \multirow{2}{*}{$\begin{array}{l}\text { Depar- } \\
\text { ture }\end{array}$} & \\
\hline & $\begin{array}{c}\text { Oceanic/ } \\
\text { Remote }\end{array}$ & $\begin{array}{l}\text { Conti- } \\
\text { nental }\end{array}$ & & Initial & Intermediate & Final & Missed $^{1}$ & & \\
\hline RNAV 10 & 10 & & & & & & & & AMC-20-12 \\
\hline RNAV 52 & & 5 & 5 & & & & & & AMC-20-04 \\
\hline RNAV 2 & & 2 & 2 & & & & & 2 & $\begin{array}{c}\text { To be } \\
\text { developed }\end{array}$ \\
\hline RNAV 1 & & 1 & 1 & 1 & 1 & & 1 & 1 & $\begin{array}{c}\text { To be } \\
\text { developed }\end{array}$ \\
\hline RNP 4 & 4 & & & & & & & & $\begin{array}{c}\text { To be } \\
\text { developed }\end{array}$ \\
\hline RNP 2 & 2 & 2 & & & & & & & $\begin{array}{c}\text { To be } \\
\text { developed }\end{array}$ \\
\hline RNP 13 & & & 1 & 1 & 1 & & 1 & 1 & $\begin{array}{c}\text { To be } \\
\text { developed }\end{array}$ \\
\hline $\begin{array}{c}\text { Advanced } \\
\text { RNP } \\
(\mathrm{A}-\mathrm{RNP}) 4\end{array}$ & $2^{5}$ & 2 or 1 & 1 & 1 & 1 & 0.3 & 1 & 1 & $\begin{array}{c}\text { To be } \\
\text { developed }\end{array}$ \\
\hline $\mathrm{RNP} A P C H$ & & & & 1 & 1 & 0.3 & 1 & & $\begin{array}{l}\text { AMC-20-27 } \\
\text { AMC-20-28 }\end{array}$ \\
\hline $\begin{array}{c}\text { RNP AR } \\
\text { APCH }\end{array}$ & & & & $1-0.1$ & $1-0.1$ & $0.3-0.1$ & $1-0.1$ & & \\
\hline RNP 0.36 & & 0.3 & 0.3 & 0.3 & 0.3 & & 0.3 & 0.3 & $\begin{array}{c}\text { To be } \\
\text { developed }\end{array}$ \\
\hline
\end{tabular}


Digits emphasized in the table appropriately are announcing about:

1. Only applies once $50 \mathrm{~m}(40 \mathrm{~m}$, Cat $\mathrm{H})$ obstacle clearance has been achieved after the start of climb.

2. RNAV 5 is an en-route navigation specification which may be used for the initial part of a STAR outside $30 \mathrm{NM}$ and above MSA.

3. The RNP 1 specification is limited to use on STARs, SIDs, the initial and intermediate segments of IAPs and the missed approach after the initial climb phase. Beyond 30 NM from the ARP, the accuracy value for alerting becomes 2 NM.

4. A-RNP also permits a range of scalable RNP lateral navigation accuracies.

5. Optional - requires higher continuity.

6. The RNP 0.3 specification is primarily intended for helicopter operations.

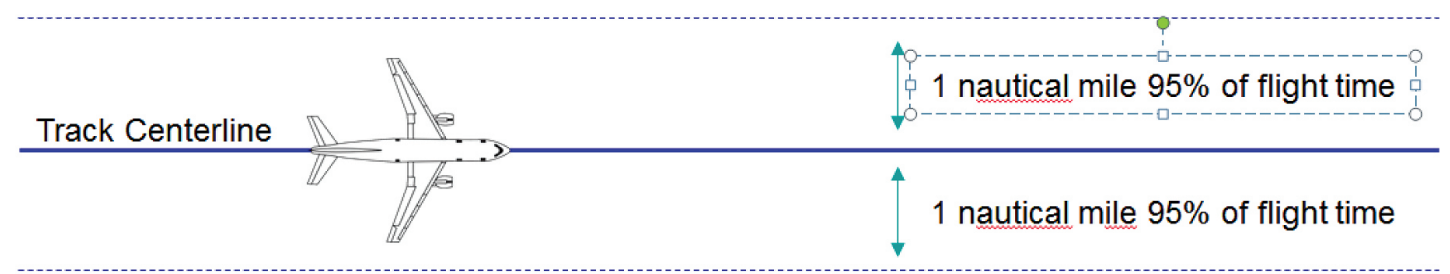

Fig. 7. The same value for RNAV 1 and RNP 1, but: RNP 1 (pre-defined track with 1 nautical miles accuracy $95 \%$ of the time and there is on-board monitoring and alerting that warns the pilot if accuracy is insufficient) however RNAV 1 (only pre-defined track with 1 nautical miles accuracy $95 \%$ of the time).

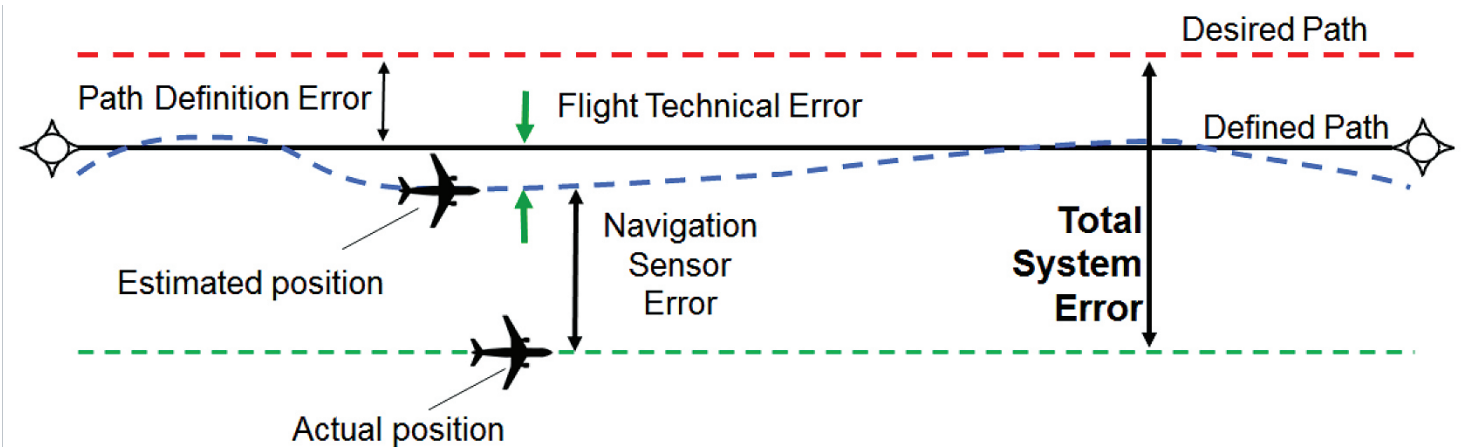

Fig. 8. Depicted of elements of TSE components.

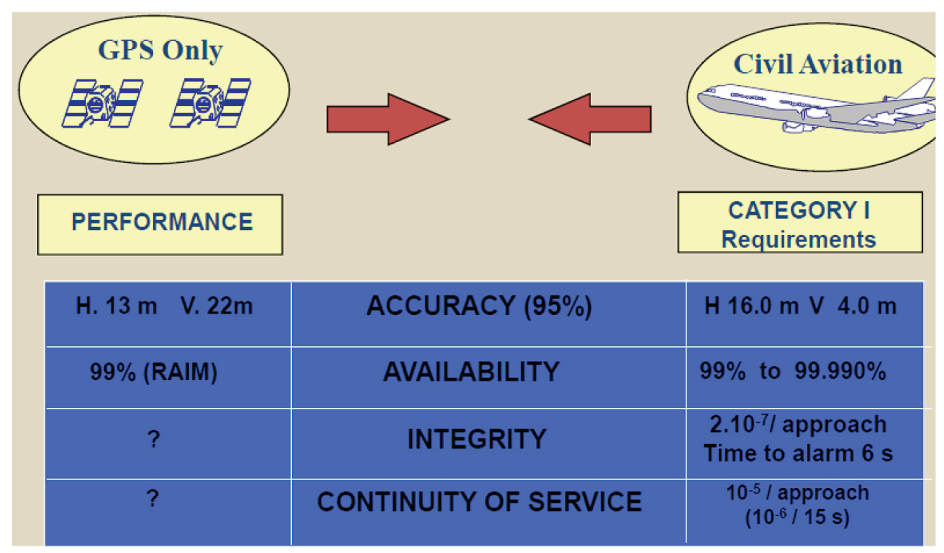

Fig. 9. Comparing parameters of systems; GPS and augmentation. 
In line with the ICAO 37th General Assembly Resolution A37-11, aerodromes are encouraged to implement RNP APCH instrument flight procedures at all instrument runway ends [7]. Missed Approaches should be designed to be flown with RNAV systems. The four types of RNP APCH described in the ICAO PBN Manual (Fig. 10):

1. Non Precision Approach (NPA), identified by LNAV minima - only lateral guidance based on the ABAS augmented GNSS signal is provided for final approach.

2. Non Precision Approach (NPA) identified by LP minima - only lateral guidance based on an SBAS augmented GNSS signal is provided for final approach.

3. Approach with vertical guidance of barometric type in final (APV Baro-VNAV) identified by LNAV/VNAV minima - lateral guidance is based on the ABAS augmented GNSS signal. Vertical guidance is based on baroaltimeter coupled with FMS.

4. Approach with SBAS type vertical guidance in final (APV SBAS) identified by LPV minimalateral and vertical guidance is based on the SBAS augmented GNSS signal $[8,9]$.

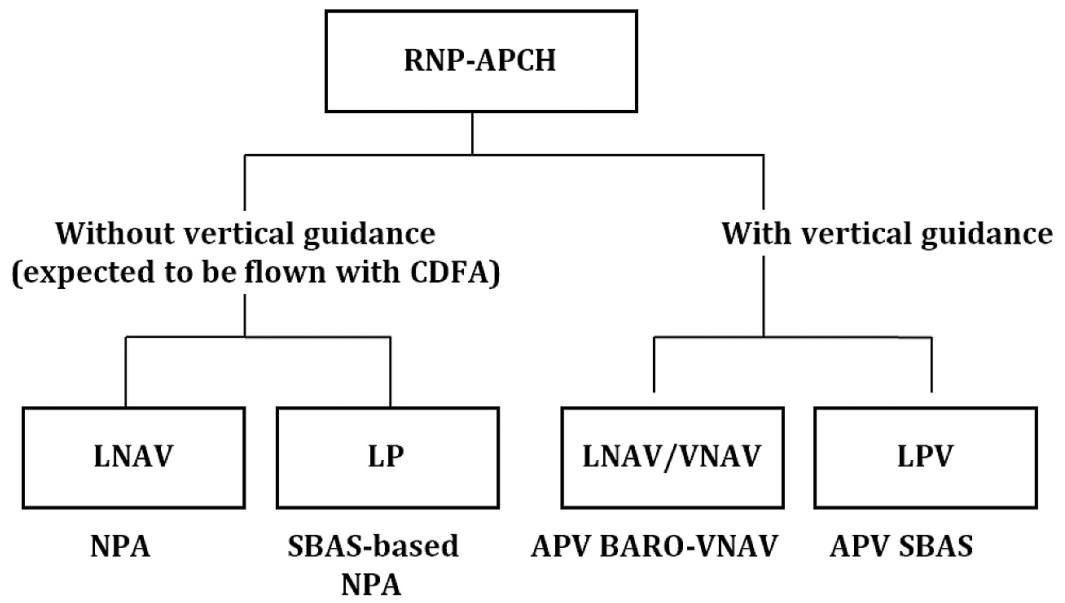

Fig. 10. The four types of RNP APCH described in the ICAO PBN Manual.

The following division of RNAV GNSS attempts is also being met:

$\Rightarrow$ LNAV (Lateral Navigation) - GPS NPA

- Final approach flown with lateral guidance (from GPS), but without vertical guidance for a controlled descent to the runway

- Flown to the LNAV MDA/H

$\Rightarrow$ LNAV/VNAV (Lateral Navigation / Vertical Navigation) - APV Baro VNAV

- Final approach flown with $556 \mathrm{~m}$ lateral limit from GPS and or SBAS and vertical guidance provided by either the barometric altimeter or SBAS

- Flown to the LNAV/VNAV DA/H

$\Rightarrow$ LPV (Localiser Performance with Vertical Guidance) - APV SBAS

- Final approach flown with 40m lateral limit enabling descent to 200-250 ft above the runway with guidance provided by SBAS

- Flown to the LPV DA/H

- There are two performance levels: APV I and APV II.

They have different descent minima depending on the kind of RNAV approach flown. ICAO PBN calls APV Baro VNAV and APV SBAS approaches as "RNP APCH”. 


\section{THE PBN IMPLEMENTATION AND EXPERIENCE}

Performance Based Navigation constitutes the global ICAO priority - Doc. 9613 is finding „PBN Manual”, planned for the completion of the undertaking oneself in Global Air Navigation Plan (GANP), Global Aviation Safety Plan (GASP) and performed action is being put together in every year given to Air Navigation Report. For his realization found appropriate funds the EU starting the SESAR (Singles European Sky ATM Research) program among others. It realization was predicted in three fundamental stages (Fig. 11), appropriate financial resources to implement optimizing advanced technologies and procedures were granted European network the ATM and implementing navigational solutions leaning against GNSS.
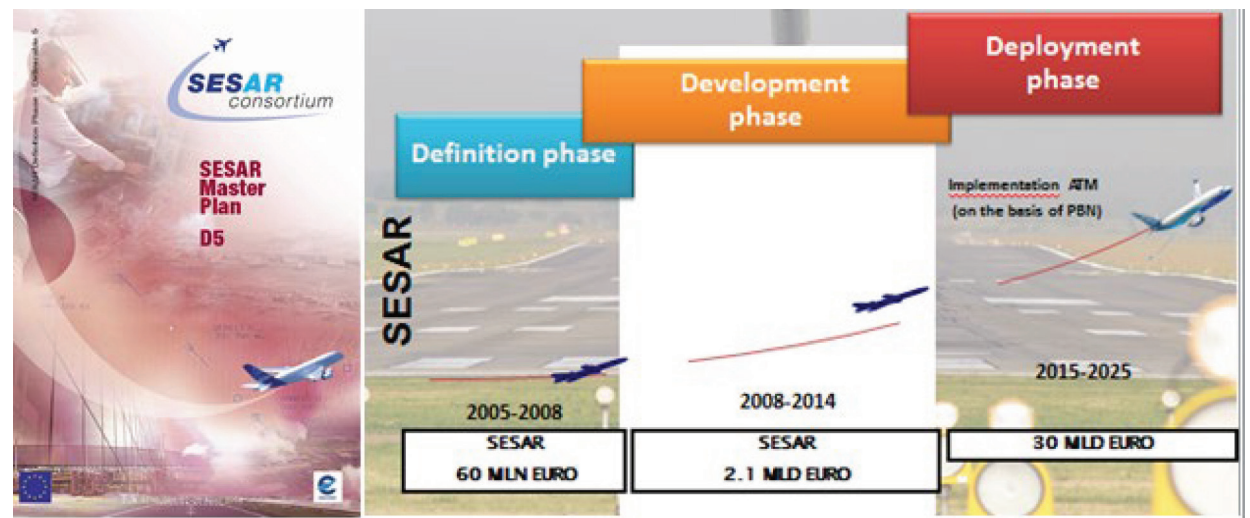

Fig. 11. FINANCING PROJECT SESAR.

The party in the global air transport of the PBN program causes the number of the benefit in different zones of activity of the man but peculiarly using it during starts and final approaches, where the greatest individual fuel consumption is appearing, an essential element constitutes environmental protections.

Economical accounts, i.e. expected profits, resulting from implementing techniques among others are also extorting the implementation of the PBN program and of the technology in the air industry:

- global reach and the universal access,

- reduced minimal operating conditions for airports, landing fields,

- greater elasticity of choice of the route of the flight and shortening the road and the time of the final approach,

- additional source of information navigational, practicable

- where particularly important - isn't able to provide the classical navigational assistance in case of airports of general aviation,

- cheap, because not requiring the extra ground infrastructure, environmentally friendly

- it is minimizing the fuel consumption, is shortening the time of the flight, is reducing the noise)

- for applying the flight in all phases.

In years from 2008 to 2014 we cooperated from PANSA (Polish Air Navigation Service Agency) and managed three projects: Helicopters Deploy GNSS in Europe HEDGE, EGNOS Introduction to the European Eastern Region MIELEC, EGNOS APV, Support ad-Hoc to Eastern Region Pre-operational in GNSS - SHERPA. They enabled to carry out resolution A-36 and A-37 by Poland concerning implementation of the program PBN. These projects were founded in frame of 
7 Framework Programme from GSA together with other countries. They required appointing the Polish team (fig. 12). As a result of conducted international works scientifically - research, applying the satellite GBAS support system for operating needs was suggested. As it turned out this system enabled to perform landing on obstructed so far support direction - the system of the precise ILS attempt is installed only on main direction. However implementation of the PBN program for this system recommended and executed procedures, enabled while tricking the single aircraft for landing:

- shortening the road for 4 nautical miles (during the flight is 8 nautical miles),

- shortening the time for 3 minutes,

- reducing fuel consumption for $82.7 \mathrm{~kg}$ ( 104 litres).

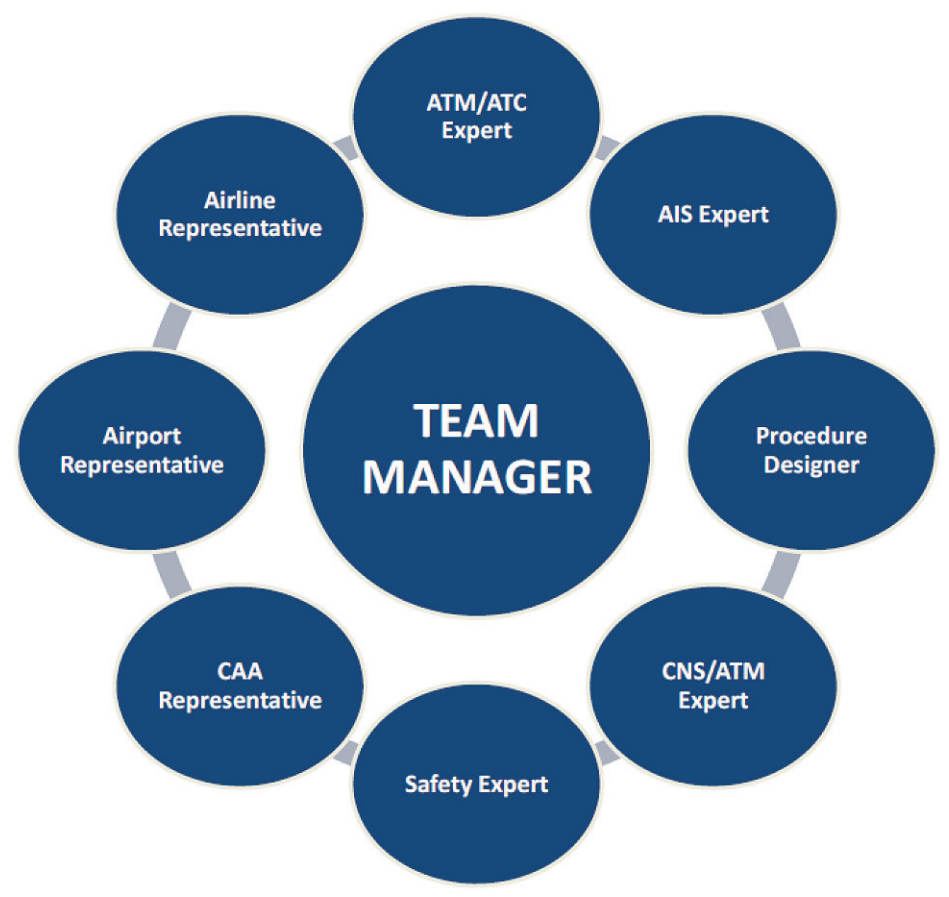

Fig. 12. Polish Team in projects: EGNOS APV, HEDGE, SHERPA.

\section{CONCLUSIONS}

Suming only outlined issues up in above material, an application is legitimate, that as a result of analysis of available literature, for performing undertakings as part of domestic and foreign projects scientifically - research [10], the following conclusions are arising - reflection:

- European Commision adopted in July new regulations about laying down airspace usage requirements and operating procedures concerning performance based navigation. It is next step in realization of the the global program PBN ICAO [11];

- At the 36th General Assembly of ICAO held in 2007, the Republic of Poland agreed to ICAO resolution A36-23 which urges all States to implement PBN;

- In future aviation concepts the use of Performance Based Navigation (PBN) is considered to be a major Air Traffic Management (ATM) concept element. ICAO has drafted standards and implementation guidance for PBN in the ICAO Doc 9613 "PBN Manual"; 
- The Based Performance Navigation Concept represents and shift from sensor-based to performance based navigation connected with criteria for navigation: accuracy, integrity, availability, continuity and functionality depending on the phase of the flight.

- Through PBN and changes in the communication, surveillance and ATM domain, many advanced navigation applications are possible to improve airspace efficiency, improve airport sustainability, reduce the environmental impact of air transport in terms of noise and emission, increase safety and improve flight efficiency;

- The completion of these projects enabled and work done and lessons learned, made the study:

- Doc: SHERPA-PANSA-NMA-D11EP "EGNOS POLAND MAKET ANALYSIS",

- Doc: SHERPA-PANSA-NSR-D21EP "Polish National Scenario Report",

- Doc: SHERPA-PANSA-ENIP-D22EP "EGNOS National Implementation Plan",

- PBN POLAND

- signed the EGNOS Working Agreement (EWA) agrement with European Satellite Services Provider (ESSP).

- ground and flight validation and implemented 28 approach procedures RNAV GNSS in polish airfield

- preparation and publication of the procedures in AIP Polska in accordance with AIRAC cycle.

- The provision of air traffic management/air navigation services (ATM/ANS) using performance-based navigation (PBN) can bring safety, capacity and efficiency benefits through the optimisation of air traffic service routes and instrument approach procedures. In order to achieve those benefits and improve the performance of the European air traffic management network, harmonised airspace usage requirements and operating procedures concerning PBN should be provided for.

- Is expected to improve the precision of approach trajectory and facilitate traffic sequencing at an earlier stage, so that fuel consumption and environmental impact in descent and arrival phases can be reduced.

- One should take up projects concerning the PBN implementation for general aviation. [12]

\section{BIBLIOGRAPHY}

[1] AC 20-105: Approval Guidance for RNP Operations and Barometric Vertical Navigation in the U.S. National Airspace System.

[2] AC 20-129: Airworthiness Approval for Vertical Navigation (VNAV) Systems for Use in the U.S. National Airspace System (NAS) and Alaska.

[3] EASA AMC 20-26: Airworthiness Approval and Operational Criteria for RNP AR Operations.

[4] EASA AMC 20-27: Airworthiness Approval and Operational Criteria for RNP Approach (RNP APCH) Operations Including APV BARO VNAV Operations.

[5] ICAO Doc 8168 - PANS-OPS.

[6] ICAO Doc 9613 - PBN Manual.

[7] ICAO Doc 9905 - RNP AR Procedure Design Manual.

[8] FAA TSO C145A: Airborne Navigation Sensors Using the Global Positioning System (GPS) Augmented by the Wide Area Augmentation System (WAAS). 
[9] FAA TSO C146A: Stand-Alone Airborne Navigation Equipment Using the Global Positioning System (GPS) Augmented by the Wide Area Augmentation System (WAAS).

[10] Szczepanik, T., Dąbrowska, J., 2009, „Wiatrakowce jako przewidywany kierunek rozwoju wiropłatów w XXI wieku,” prace Instytutu lotnictwa, 201.

[11] Rotorcraft Flying Handbook, 2000, U.S. Department of Transportation, FAA Flight Standards Service FAA-H-8083-21.

[12] Piwek, k., Wiśniowski, W., 2016, “Small air transport aircraft entry requirements evoked by flightpath 2050," Aircraft Engineering and Aerospace Technology: an International Journal, 88 . 